\title{
O apelo, a resposta e a paradoxal visibilidade do invisível: Influxo levinasiano sobre a fenomenologia francesa
}

\author{
Marcelo Fabri*
}

\section{Resumo}

$\mathrm{O}$ artigo examina o pano de fundo levinasiano da fenomenologia francesa, notadamente a de Jean-Luc Marion e, em menor medida, a de Jean-Louis Chrétien. Procura relacionar a "visão do invisível" a uma fenomenologia do apelo e da resposta. Marion afirma que aquilo que se mostra ou se dá só pode fazê-lo na medida em que se encontra recebido por um respondente. No entanto, o apelo surge de tal modo que seria impossível traçar previamente o horizonte de sua manifestação. Mais ainda: ele se exime de todo horizonte possível. O que significa uma fenomenologia sem o conceito de horizonte? Seria ainda fenomenologia? Em todo o caso, uma fenomenologia que procura ressignificar a metafísica para além de sua subordinação à ontologia.

Palavras-chave: fenomenologia, doação, invisível, apelo, resposta, Deus.

\section{The appeal, the response and the paradoxical visibility of the invisible: Levinasian influx on French phenomenology}

\begin{abstract}
The article examines the Levinasian background of French phenomenology, notably that of Jean-Luc Marion and, to a lesser extent, that of Jean-Louis Chrétien. It seeks to relate the "vision of the invisible" to a phenomenology of appeal and response. Marion states that what is shown or given can only do so as it is received by a respondent. However, the appeal arises in such a way that it would be impossible to trace the horizon of its manifestation beforehand. Even more: it avoids any possible horizon. What does a phenomenology without the concept of horizon mean? Was it
\end{abstract}

* Professor do Departamento de Filosofia da Universidade Federal de Santa Maria - RS Brasil. E-mail: fabri.ufsm@gmail.com 
still phenomenology? In any case, a phenomenology that seeks to reframe metaphysics beyond its subordination to ontology.

Keywords: phenomenology, donation, invisible, appeal, response, God.

\section{El llamamiento, la respuesta y la paradójica visibilidad de lo invisible: influjo levinasiano sobre la fenomenología francesa}

\section{Resumen}

El artículo examina el trasfondo levinasiano de la fenomenología francesa, especialmente la de J.-L.- Marion y, en menor medida, la de J.-L.- Chrétien. Trata de relacionar la "visión de lo invisible" con una fenomenología de la apelación y de la respuesta. Marion afirma que lo que se muestra o se da sólo puede hacerlo en la medida en que se encuentra recibido por un encuestado. Sin embargo, el llamamiento surge de tal modo que sería imposible trazar previamente el horizonte de su manifestación. Más aún: se exime de todo horizonte posible. ¿Qué significa una fenomenología sin el concepto de horizonte? ¿Sería todavía fenomenología? En todo caso, una fenomenología que busca ressignificar la metafísica más allá de su subordinación a la ontología.

Palabras clave: fenomenología, donación, invisible, llamada, respuesta, Dios

$\mathrm{O}$ artigo examina o pano de fundo levinasiano da fenomenologia francesa, notadamente a de Jean-Luc Marion e, em menor medida, a de Jean-Louis Chrétien. Procura relacionar a "visão do invisível" a uma fenomenologia do apelo e da resposta. Marion afirma que aquilo que se mostra ou se dá só pode fazê-lo na medida em que se encontra recebido por um respondente. No entanto, o apelo surge de tal modo que seria impossível traçar previamente o horizonte de sua manifestação. Mais ainda: ele se exime de todo horizonte possível. O que significa uma fenomenologia sem o conceito de horizonte? Seria ainda fenomenologia? Pode-se fazer fenomenologia de um "invisível" que se subtrai ao horizonte do mundo, mostrando, ao mesmo tempo, que a visão do invisível permite validar a própria definição de fenômeno? Na medida em que há fenômenos que atingem os limites da fenomenalidade (a religião é um exemplo notável disso), importa indagar sobre a possibilidade e os pressupostos da fenomenalidade. Poder-se-ia falar, assim, numa suspensão do horizonte do mundo ${ }^{1}$. Suspensão que, em Le-

\footnotetext{
Numa de suas conversas com Levinas, Marion propôs que a última etapa na direção de uma verdadeira fenomenologia seria o abandono do conceito de horizonte. Levinas não se mostrou convencido, insistindo que não há fenomenologia sem horizonte (Cf. DJIAN, 2019, p. 343-4). Para Levinas, a fenomenologia desde Husserl não fez mais que promover a ideia de horizonte, "que para ela desempenha o papel equivalente àquele do conceito no idealismo clássico; o ente surge sobre um fundo que o ultrapassa como indivíduo a partir
} 
O apelo, a resposta e a paradoxal visibilidade do invisivel: 317 Influxo levinasiano sobre a fenomenologia francesa

vinas, se torna possível graças ao encontro do rosto de outrem. Tal encontro se descreve, no início de Totalidade e Infinito (1961) como desejo do invisível. Eis por que, na primeira parte de nosso artigo, examinamos brevemente a fenomenologia levinasiana do desejo, bem como a paradoxal relação com o invisível. Tal relação será chamada também de metafísica, relação com um absolutamente outro, ou, simplesmente, transcendência.

\section{Desejo do invisível}

O desejo é uma experiência humana fundamental. Tomamos consciência de nós mesmos como desejo. Para compreender esta tese de Levinas, façamos uma breve comparação com a visão de Sartre sobre o mesmo tema, tal qual ela aparece em sua obra $O$ ser e o nada. O sujeito se determina em seu ser por um ser que ele não é. Buscar ser si mesmo, tornar-se um si, eis uma busca atravessada pela falta, pela impossibilidade de se desfazer de sua relação com os possíveis. Existimos como que à distância de nós mesmos (cf. SARTRE, 1943, p. 133). Em cada um de nossos desejos parciais (desejo de objetos do mundo, por exemplo), estamos totalmente implicados como personalidade. O que visamos com nossos desejos? Um objeto invisível. Por quê? Porque estamos perseguidos por uma totalidade que jamais alcançaremos. O objeto último do desejo é uma totalidade ausente. "Antes de Lacan, Sartre pensa o desejo como a busca de um objeto ausente, e reconhece em seus desejos empíricos a manifestação simbólica de um desejo de ser" (HAYAT, 2014, p. 115). Tudo se passa como se os desejos particulares traduzissem e traíssem a uma só vez o desejo estruturante que é, no fundo, um desejo de ser, uma tensão que nos lança para fora de nós mesmos. O desejo identificado a uma falta exprime a tensão de um ser em busca de sua própria realização (accomplissement) (HAYAT, 2014, p. 116). Seria a negação interna a marca mais profunda do desejo?

Uma das teses mais intrigantes de Levinas é esta: o desejo é desejo de um invisível. Ou seja: deseja-se porque o desejável é, justamente, o não-antecipável por excelência. O verdadeiro desejo é desejo de uma alteridade absoluta, de

do conceito" (LEVINAS, 2014, p. 35). Eis o grande ensinamento de Husserl: o pensamento visando um objeto já está implantado em horizontes insuspeitados por esta mesma visada. Tais horizontes "prestam sentido ao pensamento ingênuo" (LEVINAS, 2014, p. 14). Do ponto de vista hermenêutico, horizonte é um círculo que envolve e compreende o que podemos ver de um certo lugar. Ora, como não reconhecer que Levinas, ele próprio, abriu caminho para uma fenomenologia que suspende o conceito de horizonte? "A nudez do rosto é um desenraizamento do contexto do mundo, do mundo que significa como contexto" (LEVINAS, 1997, p. 89). Na nossa perspectiva, Marion não faz senão explorar o caminho aberto por Levinas. 
algo de que não há apropriação possível. O desejo extrai sua positividade de um não-tematizável. No desejo está fora de questão o preenchimento de um ato de visada. A intenção do desejo "está para além de tudo o que pode simplesmente completá-lo" (LEVINAS, 2014, p. 22). Desejo do invisível significa, então, a relação que se estabelece com aquilo que não é dado ou pensado à medida da consciência, tal como ocorre no par noese-noema, no sentido husserliano. Uma relação com o "mais alto" se abre graças ao desejo. Não se trata da relação a um "outro mundo", à "ordem sagrada do cosmos", nem mesmo a um ser transcendente ao mundo. O que está em jogo é a experiência aguda do humano que se dá como "consciência" e não como animalidade. "Saber ou ter consciência é ter tempo para evitar e prevenir o instante da inumanidade" (LEVINAS, 2014, p. 23). É um modo de se adiar perpetuamente a hora da traição e da violência. É a possibilidade de distinguir o humano do não-humano.

O desejo do invisível só é possível porque o eu se identifica pelo concreto do egoísmo. O corpo, a morada, o trabalho são momentos da identificação do eu. Articulam a ossatura da subjetividade. O outro é invisível porque nos vem como aquilo de que não há preenchimento, apropriação, satisfação. O desejo é uma des-ordem, isto é, difere radicalmente da ordem da necessidade. Eis por que o desejo só poderia nascer de uma subjetividade plenamente satisfeita. O que é desejar o outro? Aceitar que ele me revela o que me falta para que eu seja uma totalidade. O desejo só se produz entre termos não emparelhados. $\mathrm{O}$ eu enrolado e inebriado de sua própria vida recebe a visita ou choque de um outro que se encontra, justamente, acima do curso desta vida. O desejo se produz essencialmente contra o eu. Ele se produz, advém como uma espécie de não-persistência no mesmo, como um incessante des-ser (FORTHOMME, 1979, p. 192).

O “além” que se produz no desejo não se enquadra nos limites da análise fenomenológica. A fenomenologia é utilizada para descrever rigorosamente o que escapa à fenomenologia. O "além" se reflete no interior da totalidade e da experiência, mesmo não sendo dominado pelo pensamento. O que se vê? A impossibilidade de totalização do mesmo e do outro. Temos aqui uma fenomenologia positiva daquilo que não se totaliza na experiência, "daquilo de que não pode haver fenomenologia, mas que, mesmo assim, se fenomenaliza ${ }^{2}$ " (BENOÎST, 2015, p. 48).

2 Seguimos, aqui, a notável argumentação de Benoîst. Se, para Heidegger, o fim da metafísica significa que o sentido do ser em geral foi pensado como sentido de um ente privilegiado, e, portanto, o fim da metafísica implica o fim de tal modelo, Levinas pretende reativar o sentido da metafísica, afirmando que ela se subtrai ao sentido da ontologia. O que constitui a metafísica como tal é o motivo da transcendência. A condição da ontologia é a transcendência. Ou ainda: na perspectiva levinasiana, a questão da metafísica não 
O apelo, a resposta e a paradoxal visibilidade do invisivel: 319 Influxo levinasiano sobre a fenomenologia francesa

O in-visível surge como um "absolutamente outro", sentido que condiciona todo o aparecer. Daí poder-se dizer que o excesso em relação à totalidade não clama por uma teleologia no interior da história. Os entes são arrancados à jurisdição da história e do futuro. O sujeito é chamado à sua responsabilidade, independentemente de qualquer suposta inteligibilidade inerente ao mundo. Em cada um de seus instantes, a história pode ser julgada. Em cada etapa da trajetória humana no tempo, o existente humano pode responder como adulto e responsável. Ele pode assumir a palavra. Na totalidade dos impérios e das guerras, a palavra não existe. "Da paz, afirma o filósofo, só pode haver escatologia" (LEVINAS, 2014, p. 9). Ou seja, na história objetiva, desvelada pela guerra, a paz não vem tomar lugar.

Daí poder-se perguntar: não seria a transcendência, aspirada pelo desejo, uma simples negatividade? Não se trata de um desejo de sair do mundo real, concreto em que vivemos, criando uma espécie de ilusão de "outro mundo"? Ora, quando negamos o mundo, nós supomos nosso vínculo ao aqui embaixo. $\mathrm{O}$ "além" e a "altura" que se abrem pelo desejo não são uma simples projeção de certas qualidades de um ser finito num plano mais alto. A negação opera no plano comum do sim e do não. Mas a transcendência implica uma distância intransponível, uma ultrapassagem. Na relação de transcendência, o ser com o qual se relaciona se mantém numa exterioridade absoluta em relação ao sujeito que o pensa (cf. LEVINAS, 2014, p. 30-32). "Morrer pelo invisível: eis a metafísica" (LEVINAS, 2014, p. 23). Como entender esta proposição? Graças ao desejo, a morte deixa de ser pensada como passagem (ou aspiração) a "outro mundo" ou a "outra vida". Deixa, igualmente, de ser descrita como preocupação de um ente finito com sua própria finitude, ou como busca de perseverança no próprio ser (conatus).

O desejo abre a dimensão do "mais alto" sob a forma de um desprendimento em relação ao próprio ser. A intenção do desejo metafísico, à diferença de todos os outros desejos, não é a satisfação, mas um "além de" tudo o que poderia completá-lo. O desejo se descreve, assim, como bondade, isto é, como generosidade que se alimenta do próprio desejado (cf. LEVINAS, 2014, p. 22). O que significa a invisibilidade do desejado? Que o eu se relaciona com algo que não

está dominada pela problemática ontológica, pois o ser só se diz desde uma exterioridade (exterioridade ao ser e consequentemente à fenomenologia). Não se trata, segundo Benoîst, de restaurar a metafísica especulativa, voltada a um ser transcendente, mas sim de fazer justiça a uma dimensão que a fenomenalidade pressupõe. "O au-delà toma, então, um sentido não-ontológico. Trata-se de um 'além' dos fenômenos” (BENOÎST, 2015, p. 47). Eis o paradoxo: é somente com a análise fenomenológica que se vai descobrir e estabelecer rigorosamente este "exterior" à fenomenologia. A metafísica levinasiana terá, portanto, um sentido eminentemente fenomenológico. 
é dado, ou do qual não se pode ter uma ideia. A visão pressupõe uma adequação entre aquele que vê e aquilo que é visto. Ora, o encontro do outro produz uma espécie de inadequação. Mais do que obscuridade ou simples negação, a inadequação significa, para Levinas, uma exterioridade em relação à luz e à noite, ou ainda: uma exterioridade em relação ao conhecimento capaz de medir o cognoscível. O desejo implica uma desmesura, ele se relaciona a um "absolutamente outro" (LEVINAS, 2014, p. 23).

Fenomenologicamente, pode-se dizer que a visão do invisível é visão sem “imagem”, sem objetivação, sem totalização. Como caracterizar uma tal visão? Seria ela a interrupção da fenomenologia ou a maneira privilegiada de sua realização enquanto método? Mas como, se o eu se relaciona com algo que não é dado? Daí a pergunta: Levinas permanece no registro da fenomenologia, quando fala de transcendência, de desejo, de infinito? Veremos a seguir que Marion não apenas reivindica a fenomenologia. Quando se chega aos limites dela, conquista-se a condição para realizá-la. O desafio então é explicitar fenomenologicamente o que significa "ver o invisível", bem como a relação desse invisível com o par apelo-resposta que estrutura a subjetividade. Levinas será, assim, o ponto de partida para uma ousada e inovadora forma de se fazer fenomenologia. Vejamos de que se trata.

\section{A visão do invisível}

Jean-Luc Marion insistiu sobre a possibilidade de abertura a uma invisibilidade em sua obra O idolo e a distância, de 1977. A possibilidade do invisível se dar a ver como tal é o emblema de uma fenomenologia que, sob muitos aspectos, se inspira em Levinas para falar de uma distância intransponível, que resiste às investidas do olhar humano, sobretudo o olhar metafísico de se apropriar de Deus pela prova e pelo pensamento. O pensamento metafísico tradicional se distancia da distância (s'écarte de l'écart). Leitor de Pseudo-Dionísio, Marion afirma que "a distância não se dá a compreender, uma vez que é ela que nos compreende. A distância só é dada para ser recebida" (MARION, 1977, p. 192). Tudo se passa como se a distância nos pedisse para ser recepcionada, mas, quando tal acontece, ela nos oferece algo extraordinário: nós nos recebemos dela. Dito de outro modo, na medida em que permanece absoluta, a distância libera o espaço em que se torna possível nos receber dela. Ou seja, nós nos descobrimos entregues a nós mesmos, liberados para nós mesmos. "Admitir que o incompreensível não pode, não deve, não tem que ser compreendido significa reconhecer, receber e reverenciar a distância como distância" (MARION, 1977, p. 193). 
Há algo capaz de tornar o invisível presente? Só o ícone pode fazê-lo, já que a aparência (semblence) do invisível não dissolve a invisibilidade. Como descrever fenomenologicamente o invisível? Mostrando que ele é in-visável, algo que jamais entra na esfera do mesmo. "O ícone convoca o olhar a se ultrapassar não se fixando jamais sobre um visível, pois que o visível só se apresenta, aqui, em vista do invisível" (MARION, 1982, p. 29). Na medida em que torna visível o invisível, o ícone faz que o olhar humano jamais se aquiete diante dele. Tudo se passa como se o olhar do invisível, em pessoa, visasse o ser humano. O invisível convoca o homem, tal como um rosto nos interpela. Sob o influxo de Levinas, Marion propõe que, analogamente ao encontro de um rosto, o ícone é aquele que nos visa, que nos olha, que vê nossos olhares (MARION, 1982, p. 31). A importância da visibilidade está nisto: é através dela que o invisível nos convoca. Mas não estamos, aqui, em plena teologia mística? Como justificar fenomenologicamente o invisível?

Em trabalhos posteriores, de caráter enfaticamente fenomenológico, Marion procura argumentar que se trata de um abalo ou questionamento do quadro conceitual kantiano. Pensado a partir da categoria de modalidade, o ícone é irrégardable, isto é, incapaz de ser abarcado pelo olhar. Sendo assim, trata-se de algo que se impõe ao pensamento, sem ser apropriado por ele. O ícone não é uma simples tomada de posição de uma consciência intencional. Quando consideramos nossa condição corporal e sensível, por exemplo, percebemos que somos carne. O sentir a si mesmo e o ter consciência de que se está a sentir vai de par com a incapacidade de se subtrair a tal condição. Não posso ver minha carne como se ela fosse um objeto, uma realidade da qual tomo distância. A carne é um fenômeno que escapa às investidas do olhar, que resiste a todo esforço de constituição unívoca. Em vez de comandar, apenas nos descobrimos investidos por um efeito que se produz em nós (MARION, 2001, p. 136).

Eis o paradoxo: o fenômeno que nos advém e sobrevém inverte a ordem da fenomenalidade. Ele resulta de uma intencionalidade paradoxal, a saber, uma intencionalidade na contramão. Tomemos um exemplo recorrente em Marion.

3 A discussão especulativa desta questão pode ser encontrada de modo notável em Nicolau de Cusa, especialmente na obra $A$ visão de Deus. O problema se coloca do seguinte modo. Como é possível que Deus seja, a uma só vez, visível e invisível? A resposta, apresentada em sua mística especulativa, é esta: a visão é a essência de Deus. Ela preexiste ao ser. “Assim, Deus meu, és invisível e ao mesmo tempo visível. És invisível enquanto tu és, és visível enquanto a criatura é, a qual só é na medida em que te vê" (NICOLAU DE CUSA, 1988, p. 175). Ou seja, Deus é infinito e invisível, mas pode ser visto no visível, em qualquer ato da visão. 
No rosto de outrem, enxergamos algo que, à primeira vista, é simples absurdo: visamos o único lugar em que nada pode ser visto. Assim: "No rosto de outrem, visamos justamente o ponto em que todo espetáculo visível se confirma como impossível, em que não há nada a se ver, em que a intuição nada pode dar de visível" (MARION, 2001, p. 138). Ora, se o olhar que me visa é dirigido a mim, não se pode falar, aqui, de fenômeno. Não estamos mais na fenomenologia. Ou estamos? A resposta de Marion é notável: nem todo fenômeno se reduz a um objeto $^{4}$. Do mesmo modo, nem todo visível se deixa dominar por uma visada intencional. Tais fenômenos são justamente aqueles que nossa intencionalidade não pode manter sob seu domínio ou sua guarda. Eles são, no caso, irrégardables. O olhar de outrem como fenômeno ético (Levinas) irrompe no visível de tal modo a me fazer admitir o seguinte: submeto-me a ele como se estivesse diante do mandamento de não matar. Se cometo o assassinato, já terei perdido a fenomenalidade do rosto. $\mathrm{O}$ rosto surge, assim, como fenômeno paradoxal, pois é ele que impõe a mim o seu fenômeno, aparecendo exatamente como não abarcável pelo meu olhar (MARION, 2001, p. 141).

Qual é o propósito de Marion ao falar de fenômenos paradoxais? Sua ambição, a esse respeito, é enorme. Ele pretende fazer uma espécie de passagem da ontologia (no sentido de Heidegger) para a fenomenologia. Para tanto, busca explicitar como é possível a fenomenalidade de um fenômeno, ou seja, quer entender o que significa que algo se dê como fenômeno na intuição. $\mathrm{O}$ argumento é este: na medida em que aparece, o fenômeno, pelo menos num primeiro momento, não precisa do conceito de ser. Os conceitos metafísicos e ontológicos são, assim, substituídos pela fenomenologia (MARION, 2010, p. 86). Seja qual for o fenômeno, ele pode ser reduzido ao puro dado. O fenômeno nos atinge porque se dá a nós. Para Marion, ser, afetar, aparecer são verbos que vêm a nós como doação. A doação é indubitável não porque temos uma espécie de certeza em relação a ela, mas sim porque destitui o ego de sua soberania (MARION, 2013, p. 89). Ou seja, no mostrar-se do fenômeno o que assume a função de um guia é o próprio fenômeno, e não o ego. Na medida em que vem a mim, ou me acontece, a doação seria a figura extrema da fenomenalidade. Por exemplo: a beleza de uma obra de arte pode aparecer independentemente do quadro em que se mostra. O efeito

\footnotetext{
4 Marion não quer sair da fenomenologia, muito menos negá-la. Deseja realizá-la. Mesmo que a fenomenologia descreva fenômenos que transcendem e subvertem a ordem da fenomenalidade, trata-se buscar o originário, aquilo que aparece em sua originalidade, ou seja, é preciso deixar que os fenômenos se manifestem. O método importa apenas na medida em que caminha junto com o fenômeno. Por quê? Para proteger o fenômeno, para liberar os obstáculos à manifestação (cf. MARION, 2013, p. 14).
} 
O apelo, a resposta e a paradoxal visibilidade do invisivel: 323 Influxo levinasiano sobre a fenomenologia francesa

estético é como que "um choque que o visível provoca, emoção que invade o observador" (MARION, 2013, p. 83).

Já se pode notar o propósito mais ambicioso de Marion: a doação liberta o problema de Deus da metafísica especial, pois não se fala mais de causa sui, de princípio de razão suficiente. Como assim? É que o fenômeno não tem porquê. O fenômeno dado é descrito como acontecimento sem causa nem razão (MARION, 2013, p. 267). Mas é preciso cuidar para não se confundir o aparecer de um fenômeno como um simples fato. Trata-se de um acontecimento e, enquanto tal, de algo que simplesmente precede sua causa ou causas. Não que os acontecimentos estejam fora do mundo real e histórico, marcado por encadeamentos causais, mas sim porque nenhuma combinação de causas permite compreender um acontecimento. A tese de Marion se explicita:

O único critério em fenomenologia provém do fato - dos fenômenos que uma análise chega a exibir, daquilo que ela torna visível. O que se mostra se justifica por este mesmo fato (MARION, 2010, p. 89).

Ou seja, a doação determina todas as etapas da fenomenalidade. Ela determina a própria essência do fenômeno. O que é o fenômeno? Uma espécie de correlação entre o aparecer (Erscheinen) e o que aparece (Erscheinenden). Tal correlação, afirma Marion, se apoia sobre a doação (2013, p. 36). No fundo, a pretensão é realizar (accomplir) o que o próprio Husserl realizou, mas sem dizê-lo totalmente (MARION, 2013, p. 46). Ao aspirar ao retorno às coisas mesmas, a fenomenologia o faz rejeitando as figuras do fundamento. Ela se beneficia única e exclusivamente da figura da doação. Nesse sentido, em vez de se falar de um retorno da fenomenologia à metafísica tradicional, talvez fosse o caso de propor, com Marion, que a redução fenomenológica, no momento mesmo em que põe entre parênteses toda e qualquer tese metafísica sobre o mundo, o homem e Deus, abre a possibilidade de um tratamento novo desses "objetos": Graças à doação, a fenomenalidade dos "objetos" da metafísica pode ser constatada. Daí a pergunta: o que significa substituir um conceito metafísico de Deus (ente supremo) pelo sendo dado?

Que tipo de fenomenalidade está em jogo quando falamos em revelação? Marion afirma que se trata de um fenômeno excepcional na medida em que se insere na própria definição do fenômeno como sendo dado. A doação pode se dar sem objeto ou ente, ou seja, como um puro dado. O fenômeno excepcional da revelação é também um dado. Mas em Deus se dá a doação absolutamente, vale dizer, "sem a menor reserva nem esboço algum” (MARION, 2010, p. 93). Ele 
se deixa dar mais do que todo sendo dado. Doação sem restrição, sem reserva, sem retenção.

\section{O apelo do invisível}

Chegados a esse ponto, torna-se inevitável perguntar: em que é que o Deus da fenomenologia (expressão de Marion) se distingue do Deus da metafísica? Ora, o Deus da metafísica se difunde sem deixar de permanecer ele mesmo. $\mathrm{O}$ Deus de Espinosa, por exemplo, se exprime sem que para tanto tenha de deixar de ser a substância que ele mesmo é. Mas a doação por excelência implica uma saída de si, uma situação na qual a doação faz que o doador só possa agir sob a condição de não permanecer em si. Agostinho, Pascal e Levinas são evocados como proponentes de uma "lógica" que é simplesmente outra em relação à ordem do logos. A argumentação lógica é controlável, mas a ordem do amor, não. Não se trata de abandonar o amor da sabedoria pela sabedoria do amor, mas de compreender que são ordens totalmente diferentes. O que se passa então? A filosofia pode ser convocada pelo tribunal de ágape. A questão da metafísica aparece sob uma ordem não-ontológica, isto é, erótica (cf. MARION, 2016, p. 35 e ss.). Eis que a filosofia pode falar a língua da caridade, ultrapassando (Marion usa o verbo doubler) o que o intelecto (nôus) diz. Como poderia a metafísica falar num outro sentido, na contramão de si mesma, dizendo o que ela mesma não queria dizer?

A estratégia de Marion é sutil. Ele propõe que a teologia (e consequentemente, também a metafísica) forneça à fenomenologia certas modificações de método e de operações (cf. MARION, 2010, p. 30). A ideia fundamental é a de saturação do horizonte. Certo, toda visibilidade remete a um horizonte, mas a revelação não cabe em nenhum horizonte específico. Ela dá objetos em que a intuição ultrapassa desmedidamente a visão intencional. A influência de Levinas, mais uma vez, é decisiva: a revelação dá infinitamente mais do que a consciência pode intencionar. Os limites do horizonte fenomenológico são perturbados, saturados pela doação. Mas, para falar fenomenologicamente, o que é que se dá? Uma espécie curiosa de evidência, ou mais exatamente, o brilho de Deus produzindo uma espécie de vazio, de invisibilidade, de ausência. Graças à doação aqui considerada, Deus se torna “invisível". Doação por abandono, visto que a fenomenalidade em questão carrega, paradoxalmente, uma invisibilidade (cf. MARION, 2010, 92). Em virtude de sua própria excelência, o fenômeno Deus se expõe a não aparecer, permanecendo no abandono e na indisponibilidade. Podemos ver o invisível. Ver, apenas?

Não, pois se trata de uma relação intencional caracterizada pelo apelo. Sempre numa certa proximidade a Levinas, Marion procura mostrar que o apelo 
O apelo, a resposta e a paradoxal visibilidade do invisivel: 325 Influxo levinasiano sobre a fenomenologia francesa

é um ato fenomenológico fundador. A revolução realizada por Levinas, a esse respeito, é notável, por dois motivos. Primeiro, porque, em Levinas, a intencionalidade egológica, voltada ao objeto, se converte em contra-intencionalidade dirigida ao ego. Em segundo lugar, porque a origem de tal intencionalidade não está num ente, mas num rosto. O rosto, em sentido levinasiano, não é um ente que tem de ser. Ao lado dos fenômenos há, por assim dizer, contrafenômenos, ou, simplesmente, rostos. Os contrafenômens são chamados tais porque não se dão a ver diretamente. Eles apenas fazem pesar sobre o olhar uma responsabilidade irredutível à objetividade intencional. O que se passa quando um rosto nos visa? Um abalo (renversement) da intencionalidade e da fenomenalidade. Ou seja, do objeto visível e visado se passa ao não-visível, isto é, ao rosto (cf. MARION, 2006, p. 12).

Isto "modifica o horizonte inteiro da análise fenomenológica (...). Nós nos tornamos todos, por causa disto, levinasianos, e definitivamente" (MARION, 2006, p. 12). Em Levinas, a fenomenalidade passa da visão à palavra ${ }^{5}$. A visão que vê é produzida pelo ego, mas a palavra ouvida é algo que depende de uma recepção. Ela rompe o primado do olhar e da intuição. Mas surge a dificuldade: o apelo nada mostra. Ele apenas indica aquilo de onde provém e aquele de que testemunha: o rosto não-visível. Daí poder-se dizer que receber o rosto é sofrer um impacto, é sentir uma espécie de choque. O eu é posto no acusativo sob o impacto da contra-intencionalidade. Ora, se outrem surge para mim antes de toda compreensão e de todo conhecimento objetivo, de onde vem o apelo? De outrem? De Deus? (MARION, 2006, p. 14). Como se poderia explicitar a estrutura formal da interpelação?

\footnotetext{
5 É preciso observar que, em Levinas, há uma espécie de passagem da lógica do aparecer (fenomenologia) para a lógica do significar. "Esta lógica do significar supõe que, ali onde falamos de aparecer, já estamos sempre num outro plano que não o aparecer: a relação com Outrem” (BENOÎST, 2015, p. 58). Ora, a análise fenomenológica deve, assim, retroceder ás condições da fenomenologia enquanto discurso. Ela se volta àquilo que não pode ser objeto de fenomenologia, ou seja, àquilo cuja presença não pode ser dar (Ibid.). Marion, por sua vez, insiste na ideia de fenomenalidade, mesmo que seja fundamental reconhecer os seus limites. A regra de essência é esta: só o que for dado pode se produzir para nós. "Todo fato, todo problema e toda consciência começam por ser dados imediatos, pela imediatidade de um dado (...). Só pode surgir o que foi dado (Rien ne surgit, qui ne se donne)" (MARION, 2013, p. 91). O que há são modos paradoxais de doação, que devem ser rigorosamente descritos. O fenômeno se dá, está essencialmente ligado ao dado. Certo, a doação excede sem medida, desconcertando o sujeito. Neste caso, o rosto é uma espécie de fenômeno, mesmo que não regardable, isto é, não visado segundo a objetividade. O rosto se impõe a mim (não pode não ser visto) e, no entanto, não se pode olhá-lo como simples objeto. O que se vê? O olho experimentando claramente "sua impotência em dominar a desmedida do dado intuitivo" (MARION, 2013, p. 354).
} 
Remetendo o leitor ao parágrafo 56 de Ser e Tempo, Marion afirma que o apelo nada enuncia, não traz nenhuma informação sobre os acontecimentos do mundo. $\mathrm{O}$ apelo nada tem para contar. $\mathrm{O}$ que se passa então? Uma convocação do ser-aí a ele mesmo, ao seu poder-ser mais próprio. Somente a ipseidade do Si-mesmo está em questão no apelo. O apelo do ser (Anspruch des Seins) é o que importa, decididamente, no caso de Heidegger. Marion, evidentemente, não se satisfaz com tal solução. A origem do apelo não tem identidade fixa, não pode ser ontologicamente determinada. O Espírito sopra onde quer. "A partir do choque do apelo, não posso remontar a nenhum interpelante identificável univocamente - todos podem fazer o papel, podem fazer o apelo" (MARION, 2006, p. 16). Mas é preciso conquistar o apelo enquanto tal, sua forma mais pura. A voz do apelo é uma voz sem nome. Ele vem de Deus, de outrem, do ser? Como quer que seja, o apelo só se ouve na resposta. O adonado é aquele que responde ao dom do apelo.

Numa certa proximidade a Marion, Jean-Louis Chrétien propõe que o apelo, vindo de Deus ou dos outros, e mesmo das coisas, sempre será radicalmente primeiro em relação à questão. "Somente quando já respondi a um apelo posso me preocupar em responder a certas questões, colocando-as para mim de modo prioritário" (CHRÉTIEN, 2007, p. 4). Antes de toda questão formulada, há o apelo que tocou minha existência. É sempre uma situação específica que suscitou (chamou) as questões pelas quais me interesso. Nesse sentido, toda questão é resposta a um apelo. "Somente a resposta a um apelo abre a possibilidade de um verdadeiro questionamento" (CHRÉTIEN, 2007, p. 6). Toda palavra grave é, portanto, responsiva. Somos sempre chamados pelo ser, por Deus, pelos outros, pela natureza, etc. O apelo só se ouve na resposta. Apelo e resposta se dão simultaneamente. Eles são dados num mesmo e único ato (CHRÉTIEN, 2007, p. 15). Quando respondo a um apelo, já me descubro atrasado e em débito. Sou precedido por aquilo que me chama. Posso fugir, odiar, recusar, mas tudo isto já é responder. Só o respondente sabe o peso da questão.

Chrétien explora com erudição e sensibilidade o já extenso universo fenomenológico de Marion: ele aborda o romance, a poesia, a epopeia, a tragédia, a filosofia, a teologia. A influência de Levinas se torna clara quando propõe o primado do dizer sobre o dito, sobretudo no que diz respeito à palavra filosófica. Também em filosofia a resposta transcende a questão. As questões que realmente valem a pena são aquelas que nos escolhem. Qual o desafio que se impõe? Lutar para que o apelo não seja esquecido. Para tanto, é fundamental desdizer o já dito (o passado). Ora, o que se responde não são palavras, discursos ou textos, mas vozes. A voz que nasce pode responder de modo inusitado a tudo o que já foi 
O apelo, a resposta e a paradoxal visibilidade do invisivel: 327 Influxo levinasiano sobre a fenomenologia francesa

dito. Ou seja, aquele que participa de uma comunidade de falantes não encontra as palavras livres da orientação para outrem. O falante encontra as palavras pelas vozes de outrem. Mas, por isso mesmo, estamos sempre às voltas com a herança que recebemos. Uma voz nova pode sempre despertar possibilidades esquecidas ou abandonadas. "Só se responde a outras etapas graças às línguas históricas (tradição). Isto ultrapassa a simples filosofia” (CHRÉTIEN, 2007, p. 35).

Também o universo da teologia ganha atenção especial por parte de Chrétien. $\mathrm{O}$ apelo me captura, surge inesperadamente. Ele é o autor de minha vocação. Mas é preciso insistir num ponto: o apelo não vem preencher um vazio meu, uma expectativa minha. Ele apenas abre para mim um futuro inesperado. Avançar para tal inesperado é, simplesmente, ouvir o chamado. No caso do cristianismo, o problema se coloca da seguinte maneira: o salvador do mundo vem na contramão das expectativas e do tempo do mundo. O impossível se faz real. Temos então a ideia de um respondente que responde por nós, exatamente ali onde nos tornamos incapazes de fazê-lo. O respondente se substitui a nós, toma o nosso lugar. Caso fosse possível uma confirmação factual para esse evento, uma coisa é certa: só uma pessoa divina poderia responder de tal maneira (CHRÉTIEN, 2007, p. 211). No caso de Cristo, é o próprio respondente que vem onde nós estamos. Seu sofrer é uma forma suprema de seu próprio agir. Um sofrer no lugar do outro, no caso, da humanidade (CHRÉTIEN, 2007, p. 234). Trata-se de uma descida no abismo do sofrimento e da injustiça. E quanto a mim? É na medida em que respondo ao apelo que poderei me tornar quem serei e quem terei sido ${ }^{6}$. Ou seja, a resposta é individuante, uma vez que é a mim que o apelo é dirigido, de modo direto e pessoal. $\mathrm{Na}$ medida em que a resposta cabe a mim, e somente a mim, sou insubstituível (cf. CHRÉTIEN, 2007, p. 235).

${ }^{6}$ O influxo levinasiano sobre esta proposta é notável. A descida do criador ao nível da criatura, isto é, ao absorção do ser divino na passividade mais passiva que toda passividade coloca, para Levinas, não apenas um problema teológico, mas filosófico. É o conceito de substituição ou expiação pelos outros que se encontra em questão. Ideias teológicas desconcertam a representação, abalam o âmbito das categorias. Levinas insiste nisto: a ideia de substituição tem valor filosófico, ela pode se mostrar fenomenologicamente. Por quê? Porque é uma ideia indispensável à compreensão da subjetividade. "Manifestar-se como humilde, como aliado ao vencido, ao pobre, ao banido - é precisamente não entrar na ordem (...). A humildade desconcerta absolutamente; não é deste mundo (...). Apresentar-se nesta pobreza de exilado é interromper a coerência do universo; é praticar uma abertura na imanência sem a ela se ordenar" (LEVINAS, 1997, p. 87). Não é mais o desvelamento ou verdade do ser que se encontra em questão, mas a maneira ou modalidade da própria transcendência. A presença a si não é certeza de si, nem mesmo o assumir a própria finitude, mas risco, perigo, incerteza. A ideia de substituição e, consequentemente, do Messias é uma espécie de abalo na perseverança no próprio ser. 
Ser afetado ou atingido faz de mim insubstituível. A certeza que verdadeiramente me importa não vem de mim. Estou precisamente ali, onde posso ser atingido, interpelado, tocado. O si é pura exposição. Somente aquele que foi desconcertado pode ouvir o apelo, sabendo, ao mesmo tempo, que é preciso fazê-lo. Marion fala de "condição de possibilidade" de uma saída do discurso da ontologia. O que está em jogo é a gênese da ipseidade, é a constituição do eu. A solidariedade entre os homens depende da condição de respondente, ou seja, de um eu capaz de substituição. A substituição possui uma função transcendental: ela é a condição de possibilidade da ética (cf. MARION, 2007, p. 68).

O que significa dizer que ninguém pode me substituir? Que a ipseidade, aquilo que é mais próprio meu, está em questão. Posso ou não aceitar o apelo. Posso ou não acolher a convocação. Coloco-me em causa quando ninguém pode mais responder em meu lugar. Um exemplo paradigmático é o amor. "Cada ato de amor se inscreve em mim para sempre, desenhando-me definitivamente" (MARION, 2003, p. 22). O amor é a pergunta que não pode ser recusada. Não é a certeza sobre minha existência que conta verdadeiramente, pois estou exposto a uma incerteza radical, a saber, a uma resposta que eu não posso extrair de mim mesmo. Estou precisamente ali, onde me podem atingir. Minha resposta à convocação me coloca nas mãos de uma alteridade inassimilável. Por que dizer que o apelo é anônimo? Porque o apelo só se torna fenômeno (se mostra) mediante aquele que responde. A primeira manifestação do apelo é a resposta. A resposta abre a visibilidade, vale dizer, ela permite que o apelo se torne fenômeno.

\section{Conclusão}

O influxo levinasiano sobre Marion e Chrétien é notável e, na nossa perspectiva, imbuído de enorme fecundidade. A fenomenologia se volta para acontecimentos que constituem o "humano em nós" (expressão tão cara a Levinas!) como, por exemplo, o encontro com o outro, a responsabilidade que decorre de tal encontro, a possibilidade da revelação, a fenomenalidade do belo, a presença essencial do amor em nossa existência. São acontecimentos que dependem todos do caráter responsivo da subjetividade. Na nossa perspectiva, a estrutura apelo-resposta, embora passível de um exame crítico que remonta a influências consideráveis em Marion e Chrétien (pensemos em Kierkegaard ou no próprio Heidegger), possui um inegável aporte levinasiano, sobretudo quando se sublinha a doação como conceito fundamental de uma fenomenologia do invisível. 
O apelo, a resposta e a paradoxal visibilidade do invisivel: 329 Influxo levinasiano sobre a fenomenologia francesa

O apelo, originalmente anônimo, identificado pelo e no respondente (répons) se anuncia como um doado (donnê) e deve se receber como tal. Sua fenomenalidade não provém nem de um objeto, nem mesmo daquela de um ente - mas daquela da doação. E. Levinas atesta aliás ele próprio que outrem, como apelo, estabelece a possibilidade de uma fenomenologia da doação (...). Resta determinar se esta transcendência oferece a única doação - ou se outras imanências não poderiam juntar-se a ela, para que uma fenomenologia da doação em geral possa aflorar. Devemos a E. Levinas o fato de ter colocado esta mesma questão (MARION, 2006, p. 25).

\section{Referências}

BENOÎST, J.- Apologie de la métaphysique. In : COHEN-LEVINAS, D./SCHNELL,A.- Relire Totalité et Infini d'Emmanuel Levinas, Paris : Vrin, 2015 (p. 45-59).

CHRÉTIEN, J.-L.- Répondre. Figures de la réponse et de la responsabilité. Paris : PUF, 2007.

DJIAN, A.- L’horizon et le destin de la phénoménologie, Philosophiques 45 (2), pp. 343-364 (https://doi.org/10.7202/1055267ar).

FORTHOMME, B.- Une philosophie de la transcendance. La métaphysique d'Emmanuel Levinas, Paris : PUF, 1979.

HAYAT, P.- La liberté investie. Levinas, Paris : Kimé, 2014.

LEVINAS, E.- Entre Nós. Ensaios sobre a alteridade. Trad. Pergentino S. Pivatto (coord.), Petrópolis: Vozes, 1997.

- Totalité et infini, Paris: Le Livre de Poche, 2014.

MARION, J.-L.- L'idole et la distance, Paris: Grasset, 1977.

- Dieu sans l'être, Paris: PUF, 1982.

- De surcroît. Étude sur les phénomènes saturés, Paris: PUF, 2001.

- Le phénomène érotique, Paris: Grasset, 2003.

- "La voix sans nom"; In: Rue Descartes, Emmanuel Levinas, sous la resp. de D. Cohen-Levinas, Paris: PUF, 2006.

- La substitution et la sollicitude. Comment Levinas reprit Heidegger; In: COHEN-LEVINAS, D.-/CLÉMENT, B.- Emmanuel Levinas et les territories de la pensée, Paris: PUF, 2007, p. 51-72.

- O visível e o revelado. Trad. Joaquim Pereira, São Paulo: Loyola, 2010.

PUF, 2013. - Étant donné. Essai d'une phénoménologie de la donation, Paris:

- Doubler la métaphysique; In: Educação e Filosofia, v. 30, número especial, p. 19-39, 2016 (https://doi.org/10.14393/REVEDFIL.issn.0102-6801.v30nEspeciala2016p19a39). 
NICOLAU DE CUSA - A visão de Deus. Trad. João Maria André, Lisboa: Fundação Calouste Gulbenkian, 1988.

SARTRE, J.-P.- L'être et le néant, Paris: Gallimard, 1943.

Submetido em: 22-6-2020

Aceito em: 14-8-2020 